\title{
The validity of the diagnosis of chronic obstructive pulmonary disease in general practice
}

\author{
Lazaros Sichletidis $^{\mathrm{a}, *}$, Diamantis Chloros ${ }^{\mathrm{b}}$, Dionisios Spyratos ${ }^{\mathrm{c}}$, \\ Nicolaos Chatzidimitriou ${ }^{d}$, Petros Chatziiliadis ${ }^{e}$, Nicolaos Protopappas ${ }^{f}$, \\ Olympia Charalambidouc, Despina Pelagidouc, Elias Zarvalis', \\ Dimitros Patakas ${ }^{\mathrm{h}}$
}

a Associate Professor of Medicine, Aristotle University of Thessalonica, and Head of the Laboratory for the Investigation of Environmental Diseases, G. Papanicolaou General Hospital, Thessalonica, Greece

b Consultant Pulmonologist, Papageorgiou General Hospital, Thessalonica

c Pulmonologist, G. Papanicolaou General Hospital, Thessalonica

d Director, Health Centre of Aridaia, Pella

e The Health Centre, Krya Visi, Pella

f The Health Centre, Polycastron, Kilkis

g Consultant Cardiologist, Papageorgiou General Hospital, Thessalonica

h Professor of Medicine, Aristotle University of Thessalonica, and Pulmonary Clinic, G. Papanicolaou General Hospital, Thessalonica

Received 2nd October 2006; accepted 13th November 2006

KEYWORDS
COPD;
Diagnosis;
Spirometry;
General practitioners

Summary

Aim: To determine the validity of the diagnosis of chronic obstructive pulmonary disease (COPD) in general practice in patients given a diagnosis of COPD and treated with bronchodilators.

Methods: From the medical records of eight Health Centres in Northern Greece, 319 subjects aged over 40 years and diagnosed as "COPD" were entered into the study. All filled in a special questionnaire and were subjected to spirometry, rhinomanometry and chest X-ray.

Results: One hundred and sixty patients (50.2\%) met the GOLD criteria for COPD. Twenty-six of them were non-smokers and underwent further evaluation: blood eosinophil count, serum IgE assay, high resolution computed tomography (HRCT) scan of the chest, and echocardiography; 16 were given a different diagnosis. One hundred and fifty-nine subjects (49.8\%) with an FEV 1 / FVC ratio $>0.7$ did not meet the GOLD criteria for COPD; 71 suffered from nasal obstruction, 13 from asthma, six had restrictive pulmonary disease and 69 had no respiratory disease. Conclusion: Diagnostic errors in patients with respiratory symptoms in the primary healthcare setting are frequent. Patients suspected to have COPD should undergo spirometry testing after bronchodilation. An alternative diagnosis must be sought for non-smoking patients with irreversible airway obstruction.

(c) 2007 General Practice Airways Group. All rights reserved.

* Corresponding author.

Laboratory for the Investigation of Environmental Diseases, G. Papanicolaou Hospital, 57010 Exochi, Thessalonica, Greece

Tel: +302310 992363; fax: +302310 350316. E-mail address: sichlet@med.auth.gr 


\section{Introduction}

Chronic obstructive pulmonary disease (COPD) is a syndrome of progressive non-reversible limitation of expiratory flow caused by chronic inflammation of the airways and the lung parenchyma. ${ }^{1}$ It is one of the most frequent causes of morbidity and mortality worldwide, and in 2020 it is expected to be the third commonest cause of death after coronary artery disease and cerebrovascular disease. ${ }^{2}$

The cost of COPD treatment is constantly increasing at a time when available resources are continuously declining. ${ }^{3}$ There is therefore a need for accurate diagnosis of COPD and due consideration of potential differential diagnoses in order to minimise the risk of diagnostic confusion.

The diagnosis of COPD is usually made by general practitioners (GPs) in the primary health care setting where the necessary diagnostic equipment (spirometry) is not always available. As a result, it is probable that treatment begins without formal assessment of lung function; the diagnosis is therefore unconfirmed.

This study was designed to examine the validity of GP-made diagnoses of COPD in patients with respiratory symptoms who were receiving bronchodilator treatment.

\section{Methods}

Patients with a diagnosis of "COPD" receiving bronchodilator treatment and aged over 40 years were studied from January 2003 to January 2004. The patients were identified from the medical records of eight Primary Care Centres in two Prefectures of Central Macedonia in Greece Pella and Kilkis. These eight Primary Care Centres, covering a population of 15,500 , were randomly selected from a total of 64 centres which cover a population of about 128,000 people. The medical personnel in the Health Centres are exclusively GPs. From the 365 patients selected, 319 agreed to participate in the study (participation rate 87.4\%). After informed consent was obtained, all patients were required to complete a questionnaire, undergo spirometry and rhinomanometry, and have a postero-anterior (PA) chest X-ray.

\section{Questionnaire}

All patients filled in a special questionnaire - the British Medical Research Council (MRC-1986) questionnaire ${ }^{4}$ - which is appropriate for epidemiological research regarding the examination of the respiratory system in adults. It contains questions about chronic bronchitis, asthma, rhinitis, past medical history and thoracic surgery, smoking habits and professional background. We used the answers to support the diagnostic process and to differentiate between bronchitis, asthma and rhinitis. A smoker was considered to be a person smoking at least one cigarette daily, whereas an ex-smoker was a person who had been smoking at least one cigarette on a daily basis for at least one year and had quit smoking for at least the previous 12 months. All other subjects were regarded as non-smokers.

\section{Spirometry}

All patients were instructed not to take their bronchodilator medication for a minimum of 12 hours before spirometry. In a seated position, patients performed three consecutive violent full expiratory efforts, after a maximum inspiration, into a dry Vitalograph spirometer (Vitalograph Ltd, Buckingham, England) before and 30 minutes after bronchodilation with four puffs $(100 \mu \mathrm{g}$ each, Metered Dose Inhaler) of salbutamol. Their best effort was recorded, assuming that their two best efforts did not differ by more than $5 \%$ or $100 \mathrm{ml} .{ }^{5}$ The forced expiratory volume in one second $\left(\mathrm{FEV}_{1}\right)$ was recorded as well as the forced vital capacity (FVC). Afterwards, the $\mathrm{FEV}_{1} / \mathrm{FVC}$ ratio was calculated. The reference values given by the European Community for Coal and Steel $^{6}$ were used.

\section{Rhinomanometry}

Nasal flows were determined using anterior rhinomanometry, ${ }^{7}$ whereas the nasal resistance was determined indirectly using the Rhinotest $\mathrm{mP}$ 500 device. In order to record the flow, the patient breathed in a seated position inside a face mask which blocked one nostril. An intranasal sponge with a catheter was introduced into the nostril, transferring the pressure variations, which were recorded and electronically saved in the memory of the device. Flows were measured at 150 Pascal and reported in $\mathrm{ml} / \mathrm{sec}$. The normal flow from both nostrils is $>850 \mathrm{ml} / \mathrm{sec}^{8}$

\section{PA chest X-ray}

All patients underwent $\mathrm{X}$-ray tests in the radiology laboratories of the Health Centres.

\section{Further investigation}

Patients who showed post-bronchodilator reversibility greater than or equal to $15 \%$, and all those who had an $\mathrm{FEV}_{1} / \mathrm{FVC}$ ratio $>0.7$ and reported a history of 
asthma, had blood tests to measure serum lgE and peripheral blood eosinophil count.

Non-smoking patients with an $\mathrm{FEV}_{1} / \mathrm{FVC}$ ratio $<0.7$ had blood tests for serum IgE and eosinophil count, and had an HRCT scan of the chest and echocardiography.

In patients with a restrictive spirometry pattern, lung volumes were determined by the gas dilution method and the diffusing capacity was measured by the single breath method (Jaeger, Wurzburg, Germany).

\section{COPD diagnosis}

Existing symptoms and airway obstruction, i.e. a reduced post-bronchodilator $\mathrm{FEV}_{1} / \mathrm{FVC}$ ratio $<0.7$, were taken into account. Patients under examination who showed only symptoms and an $\mathrm{FEV}_{1} / \mathrm{FVC}$ ratio $>0.7$ were considered to be just 'at risk' (GOLD stage 0 ).

\section{Asthma diagnosis}

This was based on the history of chronic disease (an essential criterion) plus two out of the following three criteria: spirometric reversibility of $\geq 15 \%$; eosinophil count $>5 \%$; IgE $>100$ IU.

\section{Atopy diagnosis}

This was determined by a total serum IgE count of $>100 \mathrm{IU}$.

\section{Severe nasal obstruction diagnosis}

This was made on the basis of existing symptoms and rhinomanometry values $<500 \mathrm{ml} / \mathrm{sec}$.

\section{Results}

All participants reported symptoms (cough, dyspnoea and sputum production) in the MRC questionnaire. One hundred and sixty out of 319 patients (134 men and 26 women) showed symptoms and spirometric findings of irreversible bronchial obstruction $\left(\mathrm{FEV}_{1} / \mathrm{FVC}<0.7\right)$ after bronchodilation. The findings from their evaluation are shown in Table 1.

Smokers (70/134 ex-smokers and 64/134 current smokers) with bronchial obstruction had a mean age of $70 \pm 8.1$ years (130 males, 4 females), with a smoking history of $74.6 \pm 48.2$ pack-years, and had $\mathrm{FEV}_{1}$ values before and after bronchodilation of $1,435 \pm 508 \mathrm{ml}(55.4 \pm 17.3 \%$ predicted) and $1,598 \pm 525 \mathrm{ml}(59 \pm 18.5 \%$ predicted) resp-

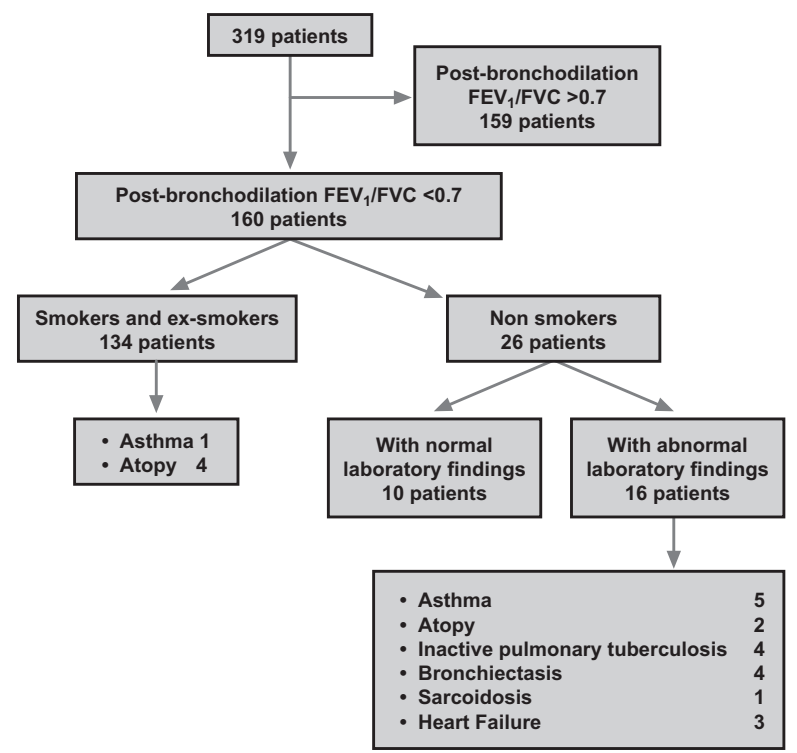

Table 1 Patients from eight Health Centres in two prefectures of Central Macedonia, Greece, who were taking bronchodilator medication with the diagnosis of COPD. Twenty-six of them underwent further investigation with blood eosinophil count, serum IgE assay, chest HRCT and echocardiography.

Post-bronchodilation $\mathrm{FEV}_{1} / \mathrm{FVC}>0.7$ 159 patients without COPD

\begin{tabular}{llr|}
\hline Nasal Obstruction: & Flow SUM $<500 \mathrm{ml} / \mathrm{sec}$ and symptoms & 71 \\
Asthma: & $\begin{array}{l}\text { Eosinophils }>5 \%, \operatorname{lgE}>100 \mathrm{IU}, \\
\text { reversibility } \geq 15 \% \text {, history }\end{array}$ & 13 \\
Pulmonary fibrosis: & $\begin{array}{l}\text { Lung volume measurement, diffusion } \\
\text { Nymptoms, Stage } 0 \text { according to }\end{array}$ & 6 \\
None: & 69
\end{tabular}

Table 2 Patients from eight Health Centres in two prefectures of Central Macedonia, Greece, receiving bronchodilator medication with an incorrect diagnosis of COPD.

ectively, while their FVC was $2,388 \pm 624 \mathrm{ml}$ $(65.3 \pm 18.5 \%$ predicted) and 2,611 $\pm 647 \mathrm{ml}$ $(71.8 \pm 10.8 \%$ predicted) respectively. The postbronchodilation $\mathrm{FEV}_{1} / \mathrm{FVC}$ ratio was $58.6 \pm 8.2 \%$ $(0.586 \pm 0.082)$.

In the remaining 159 patients who did not reveal any spirometric findings of obstructive pulmonary disease $\left(\mathrm{FEV}_{1} / \mathrm{FVC}>0.7\right.$ after bronchodilation), the diagnostic algorithm revealed one of the following diseases: nasal obstruction in 71 patients; asthma in 13; and pulmonary fibrosis in six patients. Sixty-nine patients had symptoms (cough and/or sputum production and/or dyspnoea) without any other diagnosis being made; these patients could therefore be classified as Stage 0 according to GOLD criteria (Table 2). 
Table 3 Detailed examination of non-smokers with an original diagnosis of COPD

\begin{tabular}{|c|c|c|c|c|c|c|c|c|c|}
\hline & Sex & Age & $\begin{array}{l}\text { COPD } \\
\text { Stage }\end{array}$ & $\begin{array}{c}\text { Reversibility } \\
\%\end{array}$ & $\begin{array}{c}\text { Eosinophils } \\
\%\end{array}$ & IgE UI & $\begin{array}{l}\text { Chest } \\
\text { HRCT }\end{array}$ & $\begin{array}{l}\text { Heart } \\
\text { U/S }\end{array}$ & Diagnosis \\
\hline 1 & $\mathrm{~F}$ & 70 & 1 & 12.3 & 0.8 & 80.81 & $\mathrm{BE}$ & $\mathrm{N}$ & $\mathrm{BE}$ \\
\hline 2 & M & 71 & II & 8.8 & 5.9 & 404.85 & $\mathrm{~N}$ & $\mathrm{~N}$ & BA \\
\hline 3 & $\mathrm{~F}$ & 67 & II & 3.4 & 1.3 & - & $\mathrm{BE}$ & $\mathrm{N}$ & $\mathrm{BE}$ \\
\hline 4 & $\mathrm{~F}$ & 78 & 1 & 10.4 & 3 & 307.86 & $N$ & $N$ & Atopy \\
\hline 5 & $\mathrm{~F}$ & 70 & III & 6.7 & 1.6 & 19.41 & IPT & $\mathrm{HF}$ & HF, IPT \\
\hline 6 & $\mathrm{~F}$ & 65 & I & 8.8 & 10 & 6.99 & $\mathrm{~N}$ & $\mathrm{~N}$ & $\mathrm{~N}$ \\
\hline 7 & $\mathrm{~F}$ & 45 & II & 7.5 & 5 & 54.93 & $\mathrm{BE}$ & $\mathrm{N}$ & BE \\
\hline 8 & $\mathrm{~F}$ & 58 & II & 19 & 4 & 61.69 & IPT & $N$ & IPT \\
\hline 9 & $\mathrm{~F}$ & 75 & II & 11.4 & 7 & 3.25 & $\mathrm{~N}$ & $\mathrm{~N}$ & $\mathrm{~N}$ \\
\hline 10 & M & 55 & II & 9.6 & 4 & 57.94 & IPT & $\mathrm{N}$ & IPT \\
\hline 11 & $\mathrm{~F}$ & 77 & 1 & 11.1 & 3 & 29.28 & $N$ & $\mathrm{~N}$ & $\mathrm{~N}$ \\
\hline 12 & $\mathrm{~F}$ & 63 & II & *27.5 & 2 & 18.27 & $N$ & $\mathrm{~N}$ & NLT \\
\hline 13 & $M$ & 66 & 1 & 10.5 & 3 & 60.17 & $\mathrm{~N}$ & $N$ & $\mathrm{~N}$ \\
\hline 14 & $\mathrm{~F}$ & 80 & ॥ & 11.1 & 2 & 0.13 & $\mathrm{~N}$ & $\mathrm{~N}$ & $\mathrm{~N}$ \\
\hline 15 & $\mathrm{~F}$ & 80 & II & 39.3 & 5 & 152.68 & $\mathrm{HF}$ & $\mathrm{HF}$ & HF, BA \\
\hline 16 & $\mathrm{~F}$ & 45 & II & 3.5 & 2 & 417.78 & $N$ & N & Atopy \\
\hline 17 & $\mathrm{~F}$ & 76 & II & 7.9 & 1 & 13.4 & $\mathrm{~N}$ & $\mathrm{~N}$ & $N$ \\
\hline 18 & $\mathrm{~F}$ & 66 & II & *18.2 & 2.8 & 97.97 & $N$ & $\mathrm{~N}$ & NLT \\
\hline 19 & $\mathrm{~F}$ & 77 & II & 11.8 & 3.7 & 10.10 & $\mathrm{BE}$ & $\mathrm{N}$ & $\mathrm{BE}$ \\
\hline 20 & $\mathrm{~F}$ & 66 & II & 11.4 & 2.8 & 73.58 & IPT & $\mathrm{HF}$ & HF, IPT \\
\hline 21 & $\mathrm{~F}$ & 60 & 1 & 26 & 5.9 & 109.12 & $\mathrm{~N}$ & $\mathrm{~N}$ & $\mathrm{BA}$ \\
\hline 22 & M & 65 & II & 9.2 & 13.5 & 400.77 & $\mathrm{~N}$ & $\mathrm{~N}$ & BA \\
\hline 23 & $\mathrm{~F}$ & 69 & II & 14.4 & 2.1 & 65.51 & $N$ & $\mathrm{~N}$ & $N$ \\
\hline 24 & $M$ & 73 & III & *48.9 & 3.7 & 84.43 & $N$ & $N$ & NLT \\
\hline 25 & $\mathrm{~F}$ & 69 & 1 & 16.7 & - & - & SA & $N$ & SA \\
\hline 26 & $\mathrm{~F}$ & 76 & I & 22 & 14.6 & 85.26 & $\mathrm{~N}$ & $\mathrm{~N}$ & BA \\
\hline
\end{tabular}

The GOLD staging of COPD-positive patients or those at risk for developing COPD is as follows: 69 patients were classified as Stage 0 (at risk); 34 at Stage I (mild); 95 at Stage II (moderate); 26 at Stage III (severe); and five at Stage IV (very severe COPD). Two patients in Stage I and four in Stage II were found to suffer from chronic bronchial asthma.

Fifty-four out of 160 patients with COPD $(33.8 \%)$ demonstrated reversibility equal to or greater than $15 \%$. Forty-six of them were smokers; one was found to suffer from asthma, and four had atopy. Eight patients were non-smokers; five of them had asthma and two had atopy.

Detailed evaluation of the 26 non-smokers in the

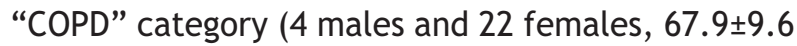
years mean age) is demonstrated in Table 3. Mean spirometric data for these patients are as follows: pre-bronchodilation $\mathrm{FEV}_{1}$ of $1,134 \pm 445 \mathrm{ml}(53.5 \pm$ 28.3 \% predicted); post-bronchodilation $\mathrm{FEV}_{1}$ of

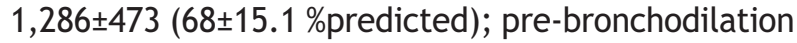


FVC of $1,830 \pm 714 \mathrm{ml}(89.8 \pm 13.9 \%$ predicted); and post-bronchodilation FVC of $1,973 \pm 712 \mathrm{ml}$ (107.8 $\pm 5.4 \%$ predicted). Their post-bronchodilation $\mathrm{FEV}_{1} / \mathrm{FVC}$ ratio was $66.5 \pm 1.7 \%(0.665 \pm 0.017)$. Diagnostic algorithm showed that five patients suffered from asthma, two had atopy, four were found with inactive pulmonary tuberculosis, four with bronchiectasis, one with sarcoidosis, and three with chronic heart failure. Certain patients suffered from more than one disease. The laboratory findings were normal in 10 subjects (three of them had an abnormal reversibility test).

\section{Discussion}

Our study showed that only 160 out of 319 clinicallydiagnosed "COPD" patients (50.2\%) had spirometrically-proven COPD with non-reversible bronchial obstruction and an $\mathrm{FEV}_{1} / \mathrm{FVC}$ ratio $<0.7$ for which they should be given bronchodilator treatment. If we add the 13 asthmatic patients who demonstrated an $\mathrm{FEV}_{1} / \mathrm{FVC}$ ratio $>0.7$ (Table 2 ), the percentage of patients properly treated with bronchodilators increases to $54.2 \%$. A significant proportion of patients $(140 / 319,43.9 \%)$ had nasal obstruction or COPD Stage 0, and had wrongly been prescribed bronchodilators.

According to the last Hellenic population census (www.statistics.gr), $42.9 \%$ of the Greek population is over 40 years old; we therefore calculate that a subgroup of 6,650 patients out of the 15,500 patients registered with the eight study Primary Care Centres will be aged over 40 . Using these figures we conclude that: a) $365 / 6,650$ (5.48\%) residents will have been diagnosed and treated for “COPD" on clinical grounds; b) 160/6,650 (2.4\%) residents would have been diagnosed correctly as having COPD $\left(\mathrm{FEV}_{1} / \mathrm{FVC}\right.$ ratio $\left.<0.7\right)$ if spirometry had been used routinely; and c) $160+13 / 6,650$ (2.6\%) would have been correctly prescribed drugs - even though most non-smoking "COPD" patients had other underlying diseases - if further investigation had taken place (detailed history, reversibility test, laboratory tests, HRCT-scan).

Comparing these figures with other studies on COPD prevalence in Greece ${ }^{9,10}$ (5.6\% of the general population are in the age range $21-80$ years and $8.4 \%$ are smokers aged $>35$ years) and Great Britain ${ }^{11}$ ( $9 \%$ of the population are aged $>45$ years old) we conclude that a significant proportion of COPD patients are not followed up by GPs. This could be attributed to the fact that we did not examine all the patients who took drugs for "COPD" (319/365), many patients do not seek medical help until their respiratory symptoms become severe, and a percentage of true COPD patients might be followed up by pulmonologists or other consultants exclusively.

It is important when establishing the diagnosis of COPD to use spirometry in primary health care, where most diagnosis and treatment of COPD patients takes place. ${ }^{12}$ GPs in Greece rarely use spirometry in daily practice, in contrast to other countries. ${ }^{13}$

However, in 1996 a postal survey among 2,548 randomly selected British GPs revealed that only $39 \%$ of those used spirometry in their practices and only $11 \%$ had direct access to a local respiratory function laboratory. ${ }^{14}$ In the UK, the situation improved following the publication of the BTS COPD guidelines in $1997 .{ }^{15} \mathrm{~A}$ survey two years later which directly contacted $209 \mathrm{GPs}$ and 102 healthcare staff showed that $50 \%$ of the GPs and $60 \%$ of the healthcare staff used a spirometer and that three out of every four physicians who did not possess a spirometer directed their respiratory patients to the nearest hospital for spirometry testing. ${ }^{16}$ In Canada and the USA, only $22 \%$ of GPs use spirometry for patients with respiratory symptoms, whereas $78 \%$ order a chest X-ray. Moreover, COPD is more commonly diagnosed in men than in women due to a gender bias. ${ }^{17}$

Twenty-six out of the 160 patients with airway obstruction were non-smokers. It is widely accepted that smoking is the most frequent cause of COPD; however, other diseases may cause an obstructive respiratory function defect as shown by spirometry. The most common are asthma and bronchiectasis, and the less common causes include obstruction of the upper airways, obstructive bronchiolitis, some interstitial pulmonary diseases (i.e. sarcoidosis, lymphangiomatosis) and other miscellaneous causes (for example, kyphoscoliosis). ${ }^{18}$ Similarly, in our study, 16 out of 26 patients, all non-smokers, had asthma, inactive tuberculosis with extensive apical fibrosis, bronchiectasis, sarcoidosis, heart failure or a combination of the above. In a long-term study from the UK, non-smokers represented $5.7 \%$ of the total number of patients with COPD, whereas their characteristic clinical features were advanced age (average age was 70 years), gender (86\% women) and a long history of respiratory symptoms (average of 7 years). ${ }^{19}$ In our study, $16.3 \%$ of non-smokers presented with airway obstruction. This difference was attributed to a large number of subjects with bronchiectasis among our patients. In Greece bronchiectasis is common in older subjects because of the high prevalence of tuberculosis in the past. ${ }^{20}$

A significant number of our patients (33.8\%) demonstrated post-bronchodilator reversibility equal to or greater than $15 \%$. This finding alone is not important in the differential diagnosis of asthma 
from COPD if the $\mathrm{FEV}_{1} / \mathrm{FVC}$ ratio remains low after bronchodilation. Significant reversibility of airway obstruction has been previously reported in a significant number of stable COPD patients, ${ }^{21}$ as well as an absence of reversibility among patients with chronic persistent asthma. ${ }^{22}$ For this reason, classifying patients as having COPD or asthma on the basis of their spirometric reversibility may be misleading and, most importantly, not enough in order to assess the progress of the disease. ${ }^{23}$ Moreover, many of our patients were already taking a combination of a long-acting beta-agonist and an inhaled corticosteroid.

Additionally, we found that five non-smokers and one smoker out of our 160 patients with COPD suffered from chronic bronchial asthma (3.7\%). Patients with asthma deserve further analysis, since recent studies have demonstrated that patients with active chronic asthma run a greater risk of developing COPD than patients with inactive asthma or without asthma, irrespective of their smoking history. ${ }^{24}$ Moreover, asthmatic patients with irreversible airways obstruction are older, have more chronic symptoms and have more severe inflammation, as well as more pathological findings on chest HRCT scans. ${ }^{25}$ The proper diagnostic classification of such cases is quite difficult.

Sixty-nine patients with chronic respiratory symptoms were found to have normal spirometry $\left(\mathrm{FEV}_{1} / \mathrm{FVC}\right.$ ratio $\left.>0.7\right)$. These patients are classified as Stage 0 according to GOLD guidelines. However, the clinical importance of this classification has to be clarified. The prognostic value of staging an individual with respiratory symptoms as GOLD stage 0 is contested $^{26}$ for the reason that regular diagnostic spirometry is necessary even for asymptomatic smokers. A recent overview article stresses that spirometry is considered to be necessary for the early diagnosis of COPD, since COPD patients may be asymptomatic until their respiratory function is significantly reduced. ${ }^{27}$

Finally, approximately $50 \%$ of the patients who were considered by their GP to suffer from COPD and who received bronchodilor medication, either suffered from another disease or showed symptoms only, without any spirometrically-proven airway obstruction, and should therefore not be on medication. This misconception certainly increases the cost of care for the National Health Care System during a period of limited financial resources.

\section{Conclusion}

Errors in the diagnosis and proper classification of COPD patients with respiratory symptoms in the primary healthcare setting are frequent. For this reason all patients suspected to have COPD should undergo spirometry testing before and after bronchodilation. The education of GPs in the utilisation of spirometry as a diagnostic tool in cases of suspected COPD is an emergency. A proper diagnosis must be sought for non-smoking patients with irreversible airway obstruction.

\section{Acknowledgements}

This study was supported by an educational fund provided by Boehringer Ingelheim Hellas.

\section{Conflicts of interest}

There are no conflicts of interest to declare.

\section{References}

1. Barnes PJ. Chronic obstructive pulmonary disease. N Engl J Med 2000;343:269-80.

2. Murray CJL, Lapez AD. The Global burden of disease: a comprehensive assessment of mortality and disability from diseases, injuries and risk factors in 1990 and projected to 2020. Cambridge, MA: Harvard University Press, 1996.

3. Global Initiative for Chronic Obstructive Lung Disease. NHLBI/WHO Workshop Report: Global Strategy for the Diagnosis, Management, and Prevention of COPD. Bethesda, MB: National Heart, Lung and Blood Institute, 2001 (NIH Publication No 2701).

4. Medical Research Council's Committee on Environmental and Occupational Health. Questionnaire on respiratory symptoms. London 1986.

5. American Thoracic Society. Standardization of spirometry, 1994 update. Am J Respir Crit Care Med 1994;152:1107-36.

6. Quanjer PH, Tammeling GJ, Cotes JE, Pedersen OF, Peslin R. Lung volumes and forced ventilatory flows. Report Working Party, Standardization of lung function tests, European Community for Steel and Coal, Official statement of the European Respiratory Society. Eur Respir J 1993;6(Suppl 16):5-40.

7. Clement PAR. Committee report on standardization of rhinomanometry. Rhinology 1984;22:151-5.

8. Bachmann W, Bachert C (eds). Die behinderte Nasenatmung: Ein diagnostisches Vademekum. Munchen Deisenhofen, Dusti - Verlag Dr. Karl Feistle, 1987, p. 25.

9. Sichletidis L, Tsiotsios I, Gavriilidis A et al. Prevalence of chronic obstructive pulmonary disease and rhinitis in northern Greece. Respiration 2005;72:270-7.

10. Tzanakis N, Anagnostopoulou U, Filaditaki V, Christaki P, Siafakas N. Prevalence of COPD in Greece. Chest 2004; 125:892-900.

11. Seamark DA, Williams $S$, Timon $S$ et al. Home or surgery based screening for COPD? Prim Care Respir J 2001;10:30-3.

12. Bellamy D. Is it possible for spirometry to become a universal measurement? In: Pearson M, Wedzicha J, eds. Chronic obstructive pulmonary disease: critical debate Blackwell Science, Malden 2003.

13. Schermer TR, Jacobs JE, Chavannes NH et al. Validity of 
spirometric testing in a general practice population of patients with chronic obstructive pulmonary disease (COPD). Thorax 2003;58:861-6.

14. Bellamy D, Hoskins G, Smith B et al. The use of spirometers in general practice. Asthma Gen Pract 1997;5:8-9.

15. BTS Guidelines for the management of chronic obstructive pulmonary disease. Thorax 1997;52(Suppl 5):S1-S28.

16. Rudolf M. Making spirometry happen. Thorax 1999;54 (Suppl 3):A43.

17. Chapman KR, Tashkin DP, Pye DJ. Gender bias in the diagnosis of COPD. Chest 2001;119:1691-5.

18. Coultas DB, Mapel DW. Undiagnosed airflow obstruction: prevalence and implications. Curr Opin Pulm Med 2003; 9:96-103.

19. Birring SS, Brightling CE, Bradding $P$ et al. Clinical, radiologic, and induced sputum features of chronic obstructive pulmonary disease in non-smokers. A descriptive study. Am J Respir Crit Care Med 2002;166:1078-83.

20. Enarson DA, Ait-Khaled N. Tuberculosis. Eur Respir Mon 2000;15:67-91.
21. Nisar M, Earis JE, Pearson MG, Carverley PM. Acute bronchodilator trials in chronic obstructive pulmonary disease. Am Rev Respir Dis 1992;146:555-9.

22. Ulrik CS, Backer V. Nonreversible airflow obstruction in life-long non-smokers with moderate to severe asthma. Eur Respir J 1999;14:892-6.

23. Calverley PMA, Burge PS, Spencer S, Anderson JA, Jones PW. Bronchodilator reversibility testing in chronic obstructive pulmonary disease. Thorax 2003;58:659-64.

24. Silva GE, Sherrill DL, Guerra S, Barbee RA. Asthma as a risk factor for COPD in a longitudinal study. Chest 2004; 126:59-65.

25. Bumbacea D, Campbell D, Nguyen L et al. Parameters associated with persistent airflow obstruction in chronic severe asthma. Eur Respir J 2004;24:122-8.

26. Vestbo J, Lange P. Can GOLD stage 0 provide information of prognostic value in chronic obstructive pulmonary disease? Am J Respir Crit Care Med 2002;166:329-32.

27. Sutherland ER, Cherniack RM. Management of chronic obstructive pulmonary disease. N Engl J Med 2004;350: 2689-97.

Available online at http://www.thepcrj.org 